\section{REVISION OF JAPANESE SAFETY STANDARDS OF BICYCLE WHEEL GUARD FOR PREVENTING CHILDHOOD INJURY DUE TO WHEEL SPOKE}

doi:10.1136/injuryprev-2012-040580a.8

\author{
${ }^{1,2}$ T Yamanaka* ${ }^{2}{ }^{K}$ Kitamura, ${ }^{2}$ Y Nishida. ${ }^{1}$ Ryokuen Children's Clinic, Japan; ${ }^{2}$ Digital \\ Human Research Center, National Institute of Advanced Industrial Science and \\ Technology (AIST), Japan
}

Background/Purpose Based on our collected 17966 cases of injury data, frequency distributions of injured parts of body (figure 1) can be calculated and it is useful for understanding trends of injuries. One of the most frequently injured parts due to bicycle is heel. We found more than $80 \%$ of the cases are injury due to wheel's spoke when children sit on a rear seat. To improve bicycle, it is necessary to collect children's body size data, especially data on the region that children's heel can reach.

Methods To clarify the reachable range of child's foot when they sit on rear seat, we conducted an experiment for measuring child's body size and we developed software for estimating reachable range based on the measured body size data. The subjects are 197 children aged from 1-year-old to 9-years-old.

Results The result shows that the average value increases about $24 \mathrm{~mm}$ as a child's age increases 1-year-old. The safety standard of bicycle wheel guard was revised in November 2011 based on our data. According to revised standard, distance between seating face of rear seat and rear wheel must be more than $350 \mathrm{~mm}$.

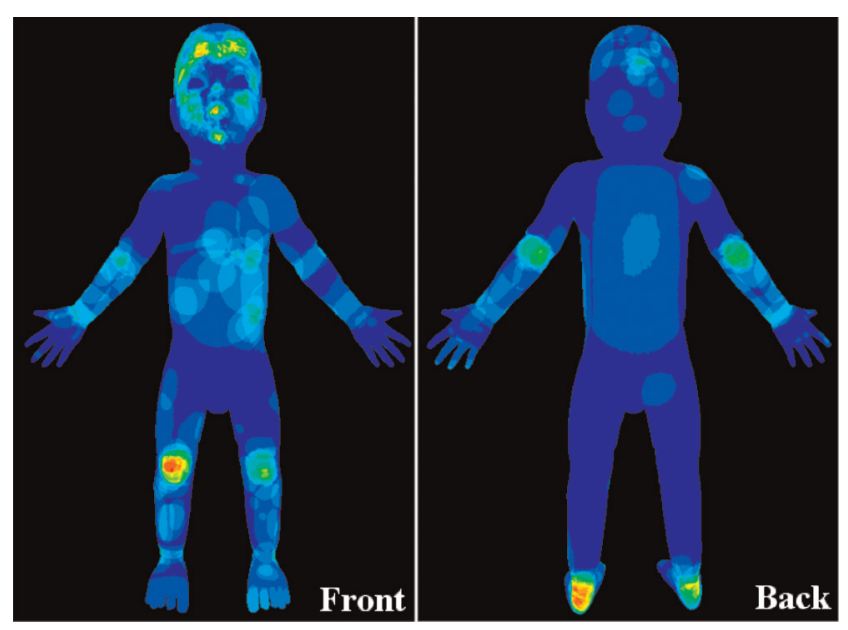

Figure 1 Frequency distribution of injury due to bicycle. 


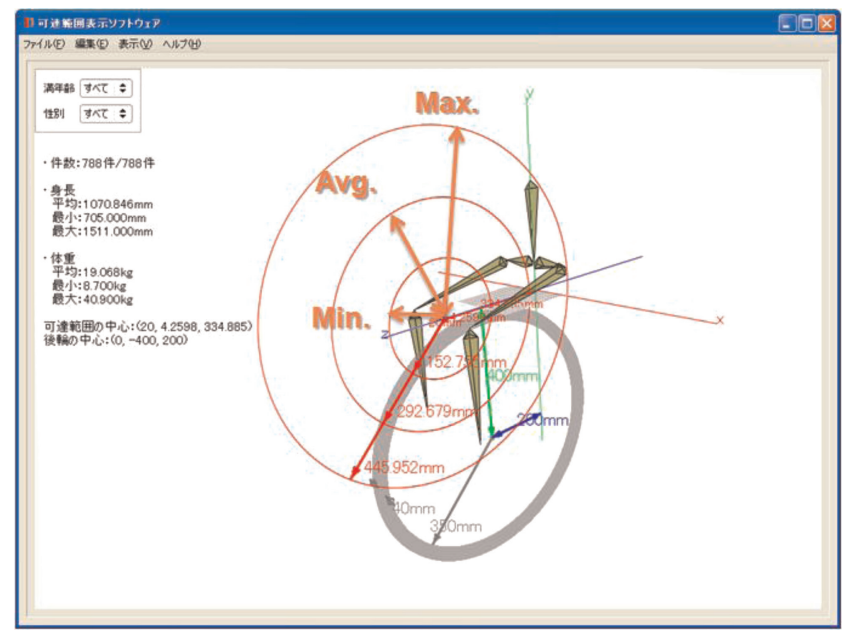

Figure 2 Visualising software of reachable range.

Conclusions We found that data on injured body parts is useful for identifying a problem due to a consumer product such as a bicycle since it allows us to analyse injury data statistically and visually. To solve the identified problem, systematic measurement of children's body size is required. 